\title{
MODIFICAÇÕES NA GEOMORFOLOGIA MARINHA A PARTIR DE ESTRUTURAS PORTUÁRIAS: O CASO DO MUCURIPE, FORTALEZA - CEARÁ
}

\author{
MODIFICATIONS IN MARINE GEOMORPHOLOGY FROM HARBOUR STRUCTURES: THE \\ CASE OF MUCURIPE, FORTALEZA - CEARÁ, NORTHEASTERN BRAZIL
}

\section{Antonio Rodrigues XIMENES NETO ${ }^{1}$, Jáder Onofre de MORAIS ${ }^{1}$, Lidriana de Souza PINHEIRO $^{2}$}

${ }^{1}$ Laboratório de Geologia e Geomorfologia Costeira e Oceânica, Universidade Estadual do Ceará, Fortaleza, CE, Brasil. Emails: antonio.lgco@gmail.com; jader.morais@uece.br

${ }^{2}$ Instituto de Ciências do Mar/UFC, Fortaleza - CE, Brasil. Email: lidriana.lgco@gmail.com

\author{
Introdução \\ Materiais e Métodos \\ Resultados e Discussões \\ Variabilidade espaço-temporal das isóbatas no Setor 1 \\ Padrões Morfológicos associados ao Setor 2 \\ Conclusões \\ Agradecimentos \\ Referências Bibliográficas
}

\begin{abstract}
RESUMO - O litoral de Fortaleza/CE apresenta desde o século XIX importantes alterações na linha de costa, principalmente associado a obras portuárias e estruturas mitigatórias de erosão. A pesquisa teve como objetivo analisar a evolução batimétrica do litoral norte de Fortaleza desde o início de operação do porto do Mucuripe em 1945. A área de estudo foi delimitada pelo espigão do Titanzinho e o emissário submarino, porém foi enfatizado o entorno portuário. Foi realizada a construção de modelos digitais batimétricos a partir das cartas náuticas da Diretoria de Hidrografia e Navegação - DHN entre 1945 e 2014. Evidenciou-se devido às constantes intervenções antrópicas a presença de dois setores: um adjacente a ponta do Mucuripe, com o substrato diretamente modificado por atividades de gerenciamento portuário e um segundo setor, que seria o restante da área submersa até o emissário submarino. O primeiro setor é marcado pela criação de áreas eminentemente deposicionais adjacentes ao molhe do Titã (efeito sombra hidrodinâmica), Titanzinho (barramento da deriva litorânea) e pelo Píer (efeito sombra do Titã e do avanço da bacia de evolução). Verifica-se que a sotamar do Titã e entornos do Píer foram sucessivamente dragados desde a década de 1950, além da criação do canal de acesso do porto na década de 1970. O segundo setor é marcado pela presença dominante de feições arenosas, destaca-se um banco longitudinal subparalelo a linha de costa de cerca de $2 \mathrm{~km}^{2}$. Esta feição apresentou grandes variações espaçotemporais desde a instalação das estruturas portuárias, no entanto a sua gênese estaria relacionada provavelmente a associação dos seguintes fatores: efeito morfodinâmico do promontório do Mucuripe no redirecionamento dos processos (pretéritos e atuais) e elevação do nível relativo do mar no Holoceno. Foi evidenciada a presença de quatro complexos rochosos - o Recife do Meireles, o Recife Grande, a Pedra do Justin, e o Recife da Velha. Ao final do setor dois (praia da Leste), tem a presença do emissário submarino com cerca de $3 \mathrm{~km}$ de comprimento e uma área de descarte de sedimentos dragados. Este setor se apresenta parcialmente modificado pelas estruturas portuárias, onde as principais alterações ocorreram nas proximidades da linha de costa (espigões e enrocamentos). Verifica-se que a morfologia do litoral submarino de Fortaleza apresentou grandes modificações nas proximidades do Porto do Mucuripe (aprofundamento do leito) e na linha de costa, devido às estruturas rígidas de proteção e operação portuária.

Palavras-Chave: Porto do Mucuripe. Estruturas Rígidas. Dragagens. Paisagem Submarina.
\end{abstract}

\begin{abstract}
The Fortaleza coast has undergone important changes in the coastline, since the 19th century, mainly due to the mitigation structures. The aim was to analyze the bathymetric evolution of the North coast of Fortaleza from the implantation in 1945 of the Mucuripe harbour. The study area is delimited by the Titanzinho groin and the wastewater outfall. Digital bathymetric models were carried out from the nautical charts of the Diretoria de Hidrografia e Navegação - DHN between 1945 and 2014. The presence of two sectors was evidenced: 1 - adjacent to the Mucuripe headland, with the substrate directly modified by port management activities; 2 - the rest of the submerged area to the outfall. The first sector is marked by the creation of eminently depositional areas due to the Titã jetty (shadow hydrodynamic effect), Titanzinho groin (obstruction of longshore current) and the Pier (Titã's hydrodynamic shadow effect and the advance of the evolution basin). It was verified that the Titã's downdrift and around the Pier were successively dredged since the 1950s, in addition to the creation of the port access channel in the 1970s. The second sector is marked by presence of sandy features, highlight a longitudinal bank of about $2 \mathrm{~km}^{2}$. This feature presented great spatial-temporal variations since the installation of the harbour structures, corroborating with pre-existing works that point out that the bank already existed before the port installation. The genesis of the bank is associated to the morphodynamic effect of the Mucuripe headland and the relative sea level rise in the Holocene. Four rocky complexes were found, as follows - Meireles, Grande, Pedra do Justin, and Velha. At the end of sector two, there is the outfall with about $3 \mathrm{~km}$ in length and a sector of dredged sediments disposal. This sector is partially modified by the port structures. It can be verified that the morphology of the submarine coast of Fortaleza shows great modifications (deepening of the bed) near the Mucuripe harbour and in the coastline, due to the rigid structures of protection and port management.
\end{abstract}

Keywords: Mucuripe Harbour. Rigid Structures. Dredging. Seascape.

\section{INTRODUÇÃOO}

A geomorfologia submarina geralmente é dividida em feições de grande escala (margens continentais, bacias oceânicas, dorsais meso- oceânicas, fossas e montes vulcânicos) e de pequena escala (como as feições resultantes da interação fluxo e substrato - sedimentos incon- 
solidados, afloramentos rochosos, rochas de praia e bioconstruções carbonática) (Heezen et al., 1959; Allen, 1982; Ashley, 1990; Boggs, 2006).

A área de estudo é delimitada entre o porto do Mucuripe e o emissário submarino, local este que apresenta importantes ações interventivas no substrato marinho (Figura 1). O litoral fortalezense apresenta desde o século XIX processos de modificações antrópicas que alteraram a dinâmica costeira (Valentini, 1994 e Paula, 2012). Na primeira parte do século passado ocorreu a construção do porto do Mucuripe e com isto segundo Morais (1981; 1972); Maia (1998); Valentini \& Rosman (1992); Valentini (1994) o molhe do porto provocou a difração de ondas que ocasionou o assoreamento portuário, formação da praia mansa e processos erosivos na orla da capital cearense. Consequentemente, vários espigões foram construídos na segunda metade do século XX para atenuar o recuo da linha de costa (Morais, 1972; Paula, 2012).

Desta forma, esta pesquisa tem como objetivo classificar as formas de fundo $\mathrm{e}$ demonstrar a evolução da morfologia submarina do litoral norte de Fortaleza/Ceará a partir da construção do porto do Mucuripe, no intuito de analisar a influência antrópica na modificação e construção da paisagem submarina.

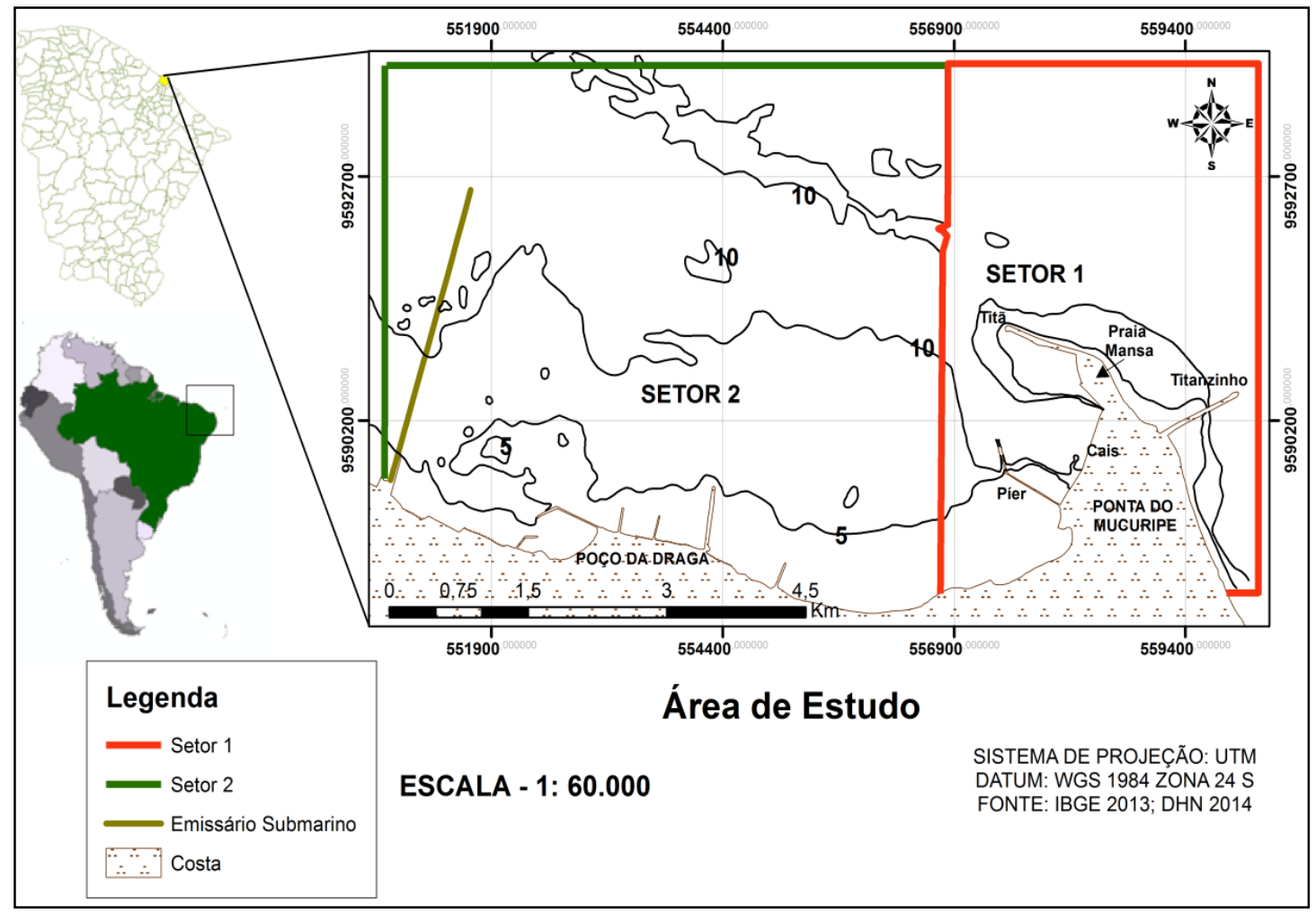

Figura 1 - Localização da área de estudo.

\section{MATERIAIS E MÉTODOS}

Foram utilizadas 13 cartas náuticas disponibilizadas pela Diretoria de Hidrografia e Navegação - DHN entre os anos de 1945 a 2014, no intuito de verificar as principais alterações no fundo conforme estas informações batimétricas eram atualizadas pela DHN. A carta de 1945 tinha uma atualização em 1952 apenas para o porto do Mucuripe. Destaca-se que a abordagem foi dividida em períodos para facilitar a visualização das modificações: 1945-1979; 1979 - 1987 e 1987-2014. Foram aplicados três softwares para a elaboração do georre- ferenciamento e confecção de mapas.

No Quantum Gis 2.0 foi realizado o georreferenciamento das cartas náuticas. Para a digitalização, geração de mapas tridimensionais, relevo e contornos batimétricos foi aplicado o Surfer 11. Para a análise espaço-temporal das isóbatas (linhas de mesma profundidade), geração de mapas de localização e temáticos foi utilizado o software ArcGis 10.1. Para a confecção dos mapas 3D e os contornos batimétricos foi utilizado da ferramenta geoestatística da interpolação pela Krigagem. 


\section{RESULTADOS E DISCUSSÕES}

A partir da análise das cartas náuticas entre o período de 1945-2014 foi realizada uma reconstituição da geomorfologia submersa. A área estudada foi dividida em dois setores entre a ponta do Mucuripe e o emissário submarino (Figura 1). O primeiro setor é representado pela área de influência direta do Porto - esta é caracterizada pela presença de alterações morfológicas no substrato devido a intervenções portuárias desde a construção do porto do Mucuripe.

O segundo setor é localizado a Oeste do canal de acesso portuário até o emissário submarino - é caracterizado pela presença de obras de proteção costeira (espigões e enrocamentos), é influenciado secundariamente pelo porto, a partir de rejeitos de dragagens, alterações nos padrões deposicionais e hidrodinâmicos. Além da presença de um banco arenoso a noroeste do molhe do Titã (Maia,

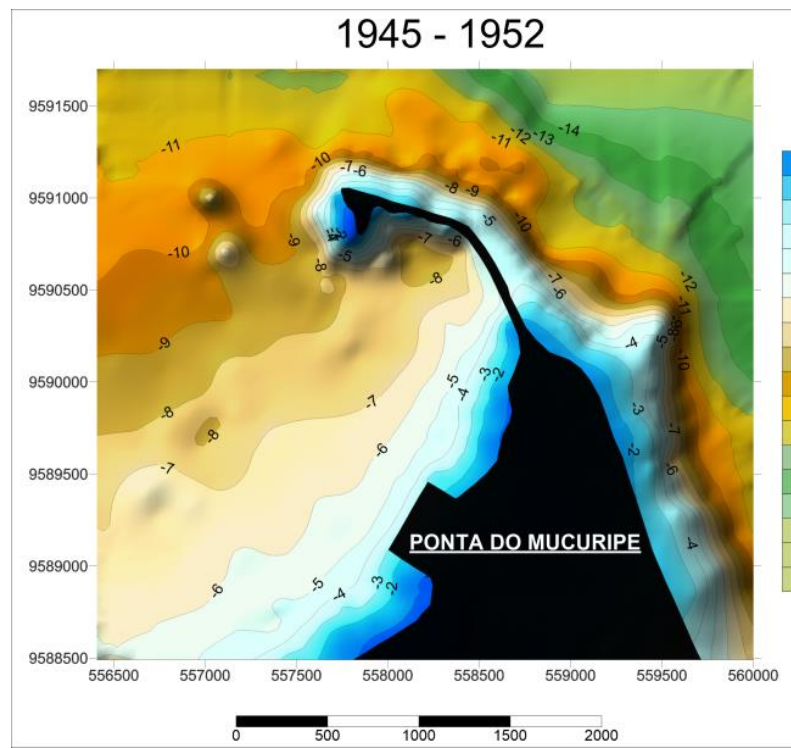

1998; Soares, 2012; Oliveira, 2013; Ximenes Neto et al., 2013, 2018).

\section{Variabilidade espaço-temporal das isóbatas no Setor 1}

Analisando a variação espaço-temporal das isóbatas adjacentes à ponta do Mucuripe foi verificado que as estruturas portuárias (molhe, espigão, cais, píer) controlaram a dinâmica morfossedimentar. Focou-se nas alterações associadas às isóbatas de 5 e 10 metros, pois elas foram as principais indicadoras de modificações batimétricas (Figuras 2 a 6).

Desde a década de 1940 há uma reorientação das isóbatas devido ao molhe do Titã e o início da construção do atual cais comercial (Figura 2). Com isto tem-se o início da progradação sedimentar a sotamar do Titã devido à difração de ondas na ponta da estrutura, fazendo desta área um ambiente de constante deposição (Morais, 1972, 1981; Pitombeira, 1976).

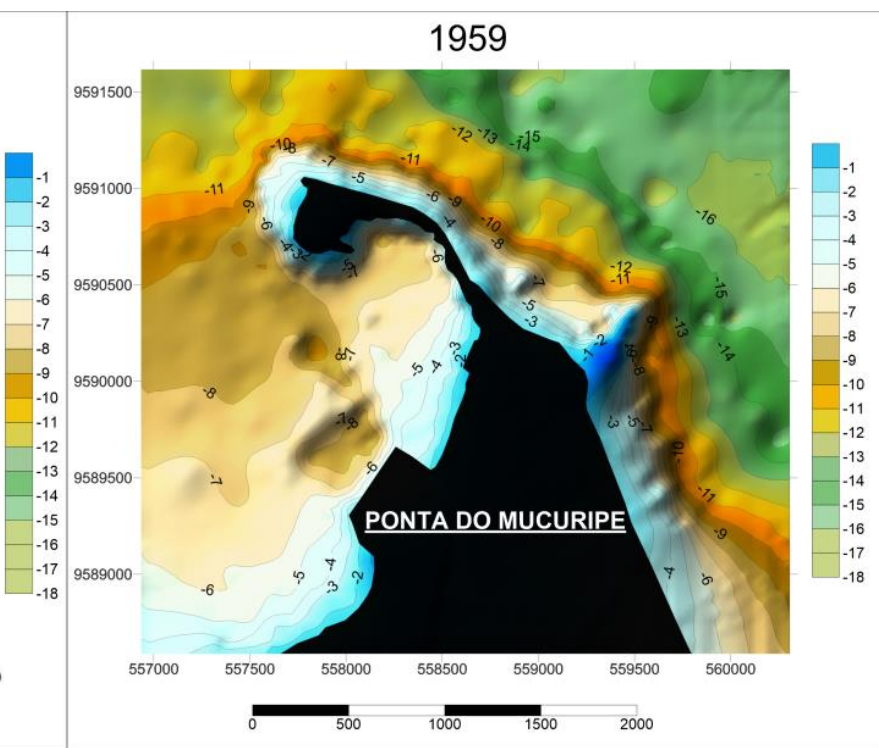

Figura 2 - Modelo Digital Batimétrico (MDB) entre 1945/1952 e 1959 e o consequente início de formação da praia Mansa e fundo progradacional à sotamar do Titã. Além da visualização da primeira dragagem para o canal de acesso.

Durante o período de 1945-1979 houve um processo progradante da isóbata de 5 metros a barlamar e adjacente a ponta do espigão do Titanzinho. Já a sotamar observou-se uma retrogradação desta isóbata e até o seu desaparecimento à barlamar do molhe do Titã (Figuras 2 a 4). Este processo ocorreu devido ao barramento no Titanzinho de sedimentos transportados pela deriva litorânea, sendo que o transporte litorâneo é orientado para oeste, em decorrência da direção do vento e das ondas (Morais, 1981; Maia, 1998). O transporte de sedimentos é unidirecional, conforme a posição da linha de costa, sendo que na Praia do Futuro ocorre de SE para NW (Morais, 1981). Durante 1959-1969 (antes e depois da construção do espigão do Titanzinho) é evidenciado progradações da isóbata de 5 metros $\left(\sim 100.000 \mathrm{~m}^{2}\right)$ no setor desabrigado - barlamar e sotamar do Titanzinho. Na ponta do Titã e na área abrigada a sotamar também se teve um processo de avanço da isóbata de 5 metros de 370. $000 \mathrm{~m}^{2}$ (Figura 2).

Neste mesmo período, a isóbata de 10 
metros apresentou de forma progradacional tanto a barlamar como a sotamar do Titã e Titanzinho ( 400.000 $\left.\mathrm{m}^{2}\right)$.

Observa-se na carta de 1959 um setor rebaixado em forma de canal com profundidade em torno de 8 metros, onde Morais (1972) se refere como um canal de acesso ao Cais. Esta foi possivelmente a primeira grande obra de dragagem associada ao porto do Mucuripe (Figura 2).

A partir de 1959 foi possível identificar um relevo positivo na forma de banco sedimentar, este fato ocorreu devido ao aumento da

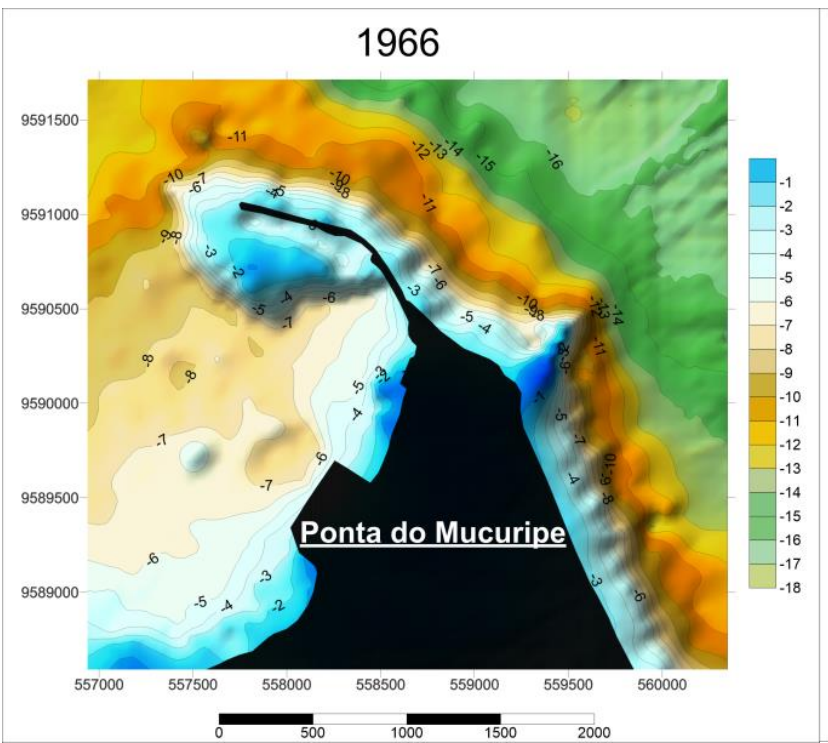

deposição sedimentar neste setor após a construção do Titã, mas é importante ressaltar que na carta de 1945-1952 este setor apresentou-se com poucos pontos batimétricos, ou seja, não podendo ser observada com nitidez esta feição (Figura 2). A partir de 1959-1969 foi possível verificar o crescimento da bacia de evolução do porto do Mucuripe. Em 1969 temse a construção do Titanzinho com o intuito de diminuir o assoreamento no interior do porto (Morais, 1972, figura 3). Observa-se o prolongamento da ponta do molhe e o crescimento da Praia Mansa.

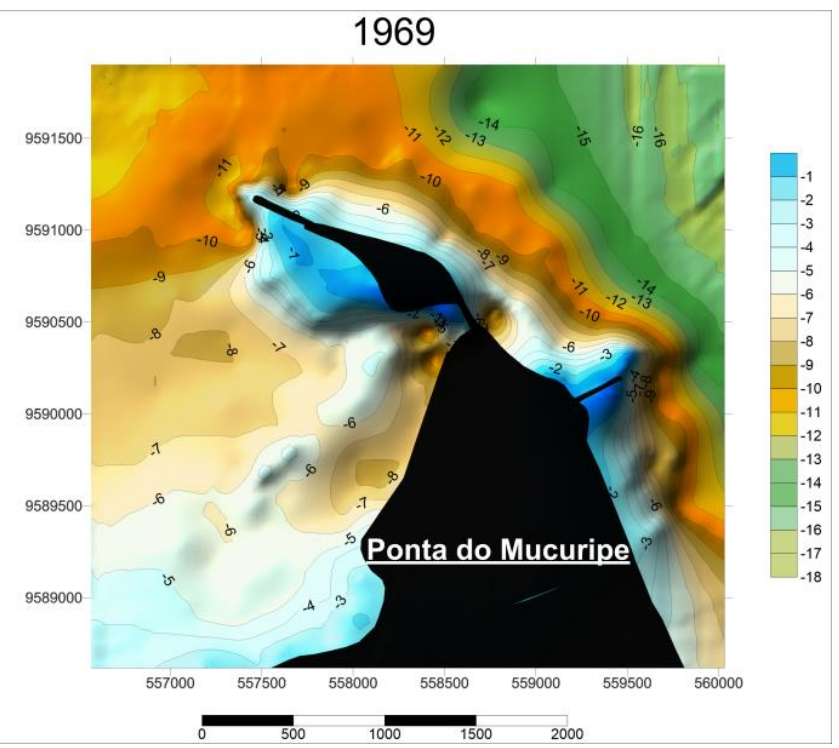

Figura 3 - MDB entre 1966 e 1969. Destruição (1966) e reaparecimento da Praia Mansa (1969) e avanço progradacional de sedimentação no entorno abrigado do Titã. Na carta de 1969 é verificada a construção do Titanzinho e prolongamento do Titã.

Observa-se que na carta de 1969 o molhe do Titã está prolongado e se verificou dragagens na bacia de evolução portuária e o desaparecimento da isóbata de 5 metros, associado à construção do cais, aterrando uma área de cerca de $320.000 \mathrm{~m}^{2}$ (Ximenes Neto \& Morais, 2015). A isóbata de 5 metros reaparece apenas na parte SW do cais. Neste período não se verifica maiores alterações na isóbata de 10 metros neste setor (Figura 3).

Após a finalização da ampliação do Titanzinho (1969-1979) foi verificado no sentido barlamar do Titanzinho a progradação da isóbata de 5 metros $\left(125.000 \mathrm{~m}^{2}\right)$, o sotamar apresentou acumulação tanto quanto $\mathrm{o}$ recuo. $\mathrm{Na}$ área abrigada foi verificado um avanço $\left(41.000 \mathrm{~m}^{2}\right) \mathrm{e}$ recuo $\left(19.000 \mathrm{~m}^{2}\right)$ da isóbata de 5 metros.

No fim do cais observa-se a construção do píer petroleiro e um processo progradante de $400.000 \mathrm{~m}^{2}$. Em relação à isóbata de 10 metros foi observado devido à criação do canal de acesso principal, o recuo desta isóbata em 2.000 metros (Figura 4). Este canal apresentou inicialmente profundidades variando de 9,3 a 10,7 metros.

A partir de 1979 é evidenciado um desaparecimento da isóbata de 5 metros na inflexão (mudança de NW-SE para WNWESE) do Titã até a ponta da estrutura e consequentemente a aproximação da isóbata de 3 e um 1 metro (a partir da carta de 1987 defronte a ponta, a isóbata de 5 metros se readapta).

A isóbata de 10 metros apresentou progradação de $40.000 \mathrm{~m}^{2}$ e uma retrogradação de $8.500 \mathrm{~m}^{2}$ antes do Titanzinho. Logo após o espigão e início do barlamar do Titã tem-se um avanço de $65.000 \mathrm{~m}^{2}$ e um recuo de $75.000 \mathrm{~m}^{2}$. $\mathrm{Na}$ ponta do Titã ocorreu avanço de cerca de $230.000 \mathrm{~m}^{2}$. 
Em 1974, com a sua capacidade de retenção de sedimentos esgotada, o espigão do Titanzinho foi prolongado de 550 para 990 metros (CDC, 2010).

$\mathrm{Na}$ carta de 1979 observa-se que o píer petroleiro ocasionou uma retenção de sedimentos e progradação neste setor. Três Fundos Progradacionais (Titã, Titanzinho e Píer) foram criados, destacando-se o avanço das isóbatas de 1,3 e 5 metros, principalmente a sotamar do Titã. A evolução morfossedimentar progradante a sotamar do molhe do Titã observado desde a carta de 1945-1952 foi responsável pela formação da Praia Mansa (Morais, 1972, figura 4).

$O$ fundo progradacional associado ao Titanzinho ocorre pelo barramento da deriva litorânea e o consequente acúmulo a barlamar do espigão; o fundo progradacional do Titã ocorreu devido ao efeito "sombra hidrodinâmica" e a difração de ondas na ponta da estrutura; já o fundo progradacional do Píer é devido à estrutura em si, ao efeito sombra hidrodinâmica do molhe, ao prolongamento do fundo progradacional do Titã e da bacia de evolução.

Entre 1979 e 1987 verifica-se uma retrogradação das isóbatas de 10 e 5 metros a barlamar e no entorno do Titanzinho (Figura 4). Destaca-se o alargamento do canal de acesso e a reorientação morfológica da isobatimétrica de 10 metros. Em 1987, o canal apresenta profundidades variando de 10,1 a 12,9 metros.

Entre 1979-1987 a isóbata de 5 metros a barlamar do Titanzinho apresentou-se de caráter retrogradacional $\left(145.000 \quad \mathrm{~m}^{2}\right)$, principalmente na porção sul a 500 metros do Titanzinho. Já na área abrigada (sotamar do Titã) esta isóbata se comporta como progradacional $\left(70.000 \mathrm{~m}^{2}\right)$ e levemente retrogradacional $\left(3.000 \mathrm{~m}^{2}\right)$. $\mathrm{Na}$ área do píer ocorreu um processo progradante de $\sim 180.000 \mathrm{~m}^{2}$, mas também foi verificado um recuo de $\sim 17.000 \mathrm{~m}^{2}$. Em relação à isóbata de 10 metros, verifica-se recuo de $\sim 64.000 \mathrm{~m}^{2}$ no barlamar do Titanzinho. Já a sotamar e a barlamar do Titã não se verifica tantas mudanças. Verifica-se um processo de recuo da isóbata de 10 metros sobre a ponta logo a sotamar, de $35.000 \mathrm{~m}^{2}$.

No canal foi verificada uma tendência de aumento da área correspondente a isóbata de 10 metros no canal dentro da área abrigada devido a dragagens (passando de $287.000 \mathrm{~m}^{2}$ em 1979 para $\sim 640.000 \mathrm{~m}^{2}$ em 1987, figura 4). É importante salientar que este avanço da isóbata de 10 metros não é devido a uma condicionante progradante e/ou erosiva e sim devido às sucessivas dragagens realizadas para 0 aprofundamento do canal do porto.

Um fator importante no período anterior ao Titanzinho até 1979 foi que a variação espaçotemporal da isóbata de 5 metros apresentou apenas processos progradacionais associados ao barlamar do Titanzinho, porém a partir de 1987 é evidenciado um processo erosional a 500 metros sul do espigão. Sendo assim, no período de 1959-1987 foram evidenciados dois setores associados ao barlamar do Titanzinho: sul (erosão - $47.140 \mathrm{~m}^{2}$ ) e nas proximidades da estrutura (acumulação - 64.400m², figuras 2 a 4).

A partir de 1987, não foi realizada mais análises isobatimétricas no entorno do Titanzinho devido à falta de atualização de dados neste setor. Foram realizadas apenas nos entornos do Titã e do Píer (Figuras 5 e 6). A isóbata de 5 metros em quase todo Titã apresentou pouca alteração, a pequena exceção foi na área do setor abrigado (dragagem recuando cerca de $50.000 \mathrm{~m}^{2}$ ), além de haver um pequeno acúmulo de $\sim 10.000 \mathrm{~m}^{2}$ na ponta do Titã.

$\mathrm{Na}$ área adjacente ao píer petroleiro também em virtude da dragagem apresentou um recuo $\left(75.000 \mathrm{~m}^{2}\right)$, já a sotamar do píer tem-se um acúmulo $\left(55.000 \mathrm{~m}^{2}\right)$. Já a isóbata de 10 metros apresentou uma pequena progradação defronte a ponta do titã de $\sim 20.000 \mathrm{~m}^{2}$. No canal é verificado um grande alargamento de $640.000 \mathrm{~m}^{2}$ para $1.300 .000 \mathrm{~m}^{2}$.

$\mathrm{Na}$ carta de 2002 foi observado que o canal apresentou variações de profundidades de 9,5 a 12,3 metros, ou seja, apresentou um processo de assoreamento (Figura 5). Este fato ocorre devido ao efeito "sombra hidrodinâmica" do Titã.

Em 2010, o canal de acesso apresentou profundidades entre 9,9 a 12,5 metros (Figura 5). Já em 2014, a variação foi entre 10 a 14,6 metros, mas há o predomínio de 13 a 14 metros (Figura 6). As menores profundidades ocorreram nas extremidades do canal, principalmente no Cais. Antes da instalação do porto do Mucuripe, a área compreendida pelo atual canal (no setor abrigado do porto) apresentava profundidades variando de 1 a 9,5 metros. 
O setor submerso defronte ao Cais Comercial teve a destruição/aterramento das profundidades inferiores a 5 metros, fazendo

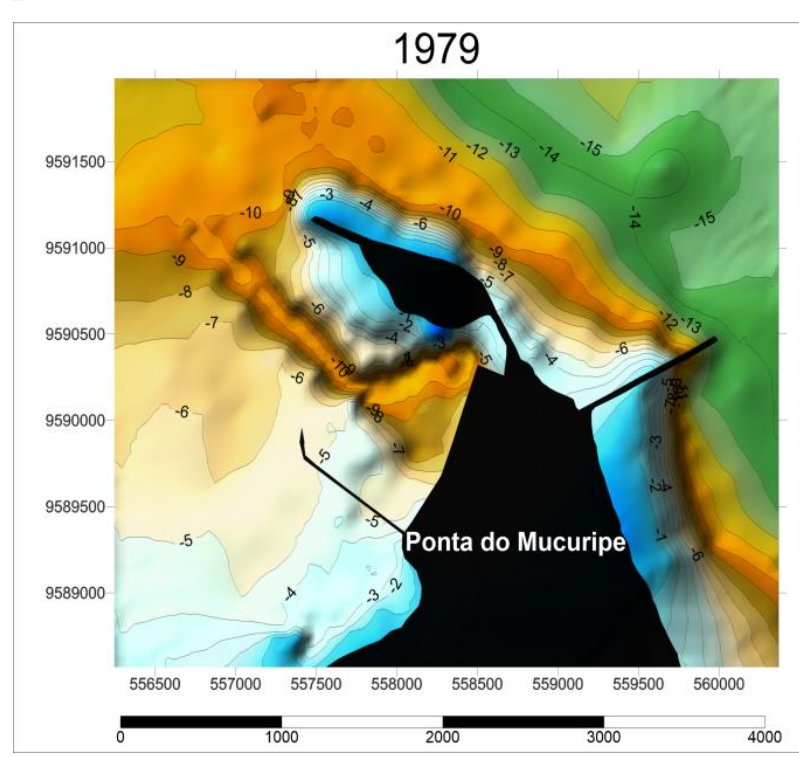

com que estas isóbatas $(1,2,3,4$ e 5) migrassem em direção offshore. Processo este de natureza artificial.

Figura 4 - MDB entre 1979 e 1987. Verifica-se a criação do canal de acesso principal (1979), alargamento (1987) e prolongamento do Titanzinho (de 550 metros para 990 metros) com a consequente evolução progradacional.
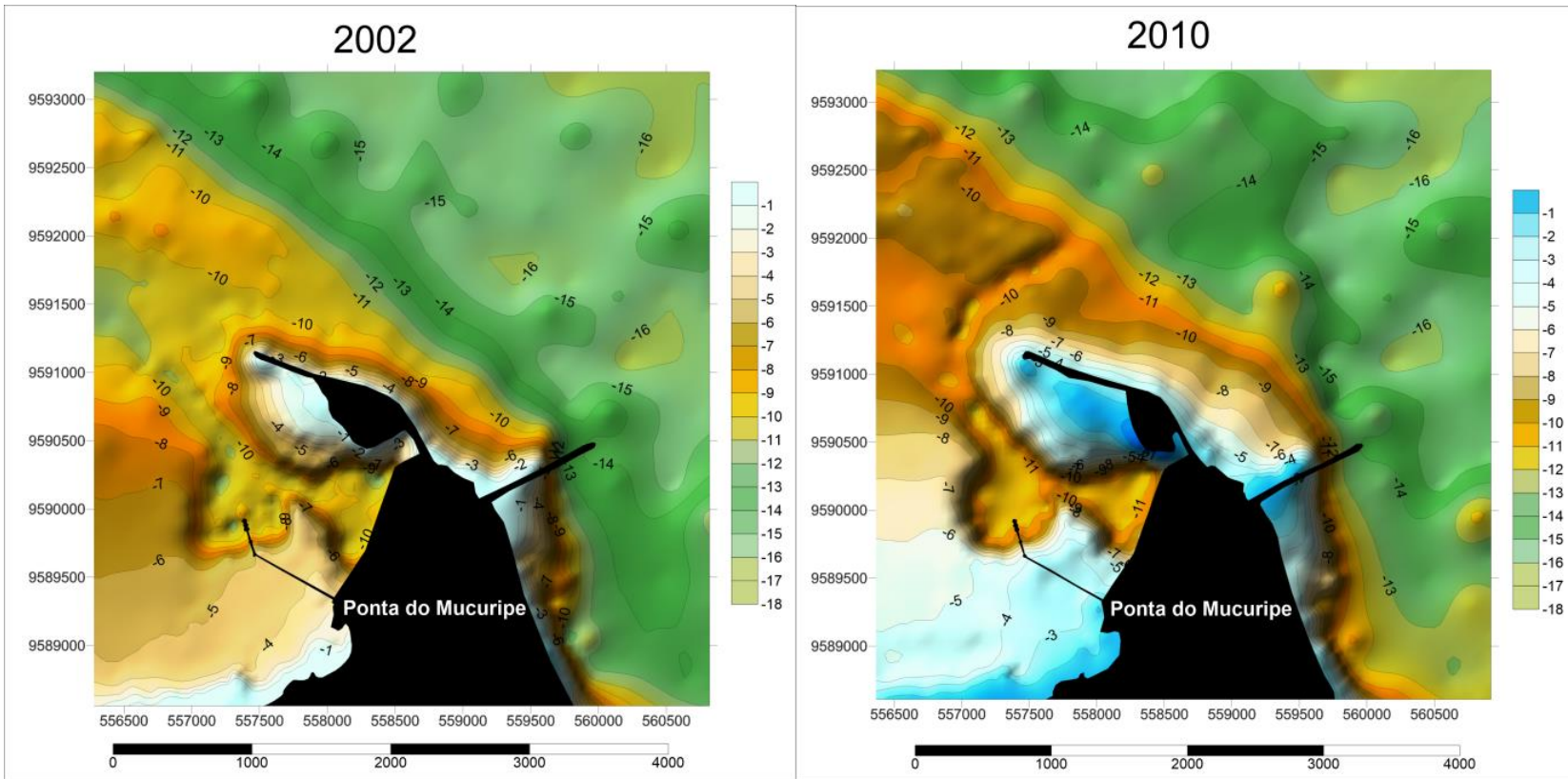

Figura 5 - MDB entre 2002 e 2010. Destaca-se o novo alargamento (2002) e prolongamento (2010) do canal de acesso.

No período de 1987-2014 foi observado que a isóbata de 5 metros retrogradou na bacia de evolução e no entorno do píer petroleiro devido ao fato da realização de novas dragagens nas décadas de 1990 e 2000 (Figuras 4 a 6).

Já em relação à isóbata de 10 metros, as principais alterações se deram no canal de acesso devido ao seu prolongamento e na bacia de evolução devido às dragagens. A área do sotamar do Titã (entre o Molhe e o Píer) apresentou um constante processo de assoreamento, onde as sucessivas dragagens

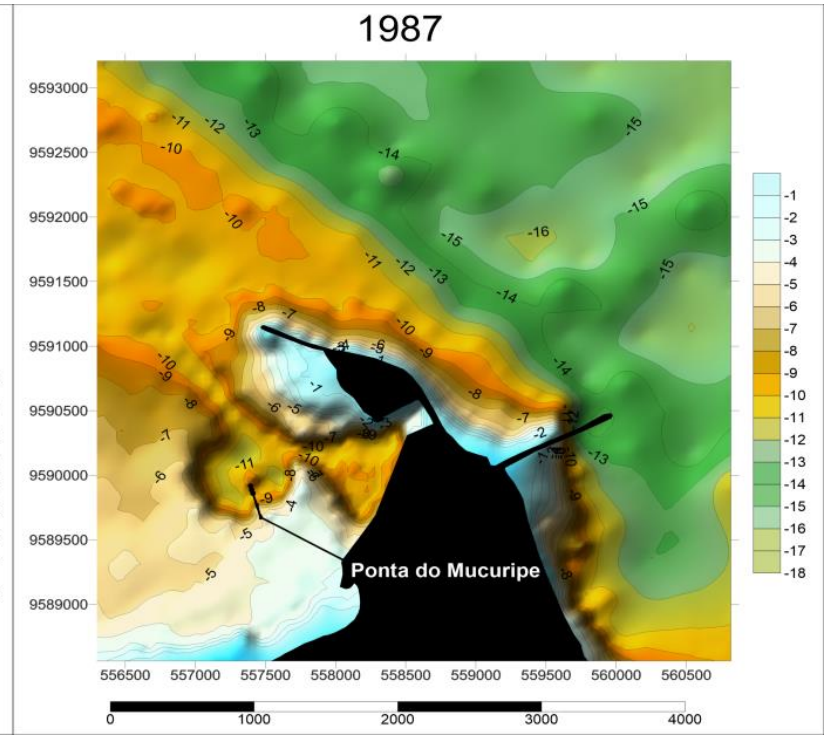


Verificou-se que na análise destes 70 anos, o morfossedimentar devido as estruturas de setor 1 foi bastante alterado do ponto de vista proteção portuária.

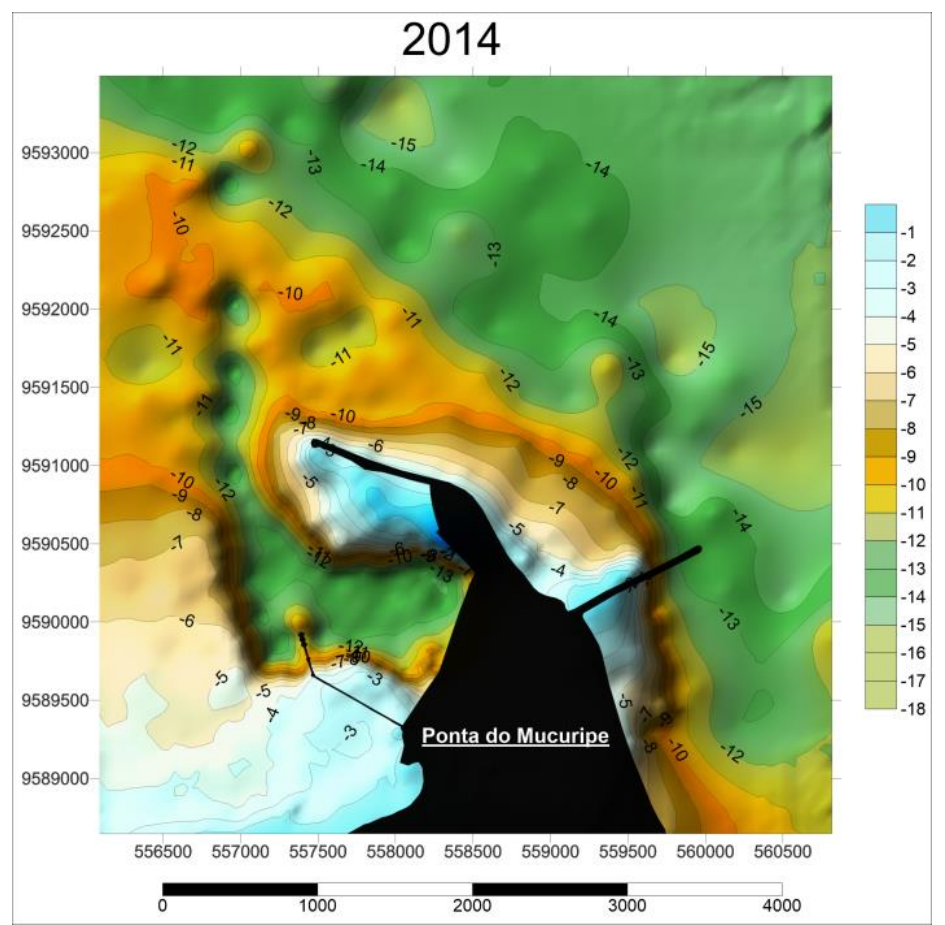

Figura 6 - MDB referente a 2014. Com a atual situação do canal de acesso possuindo profundidades de até 14 metros e comprimento de 1200 metros.

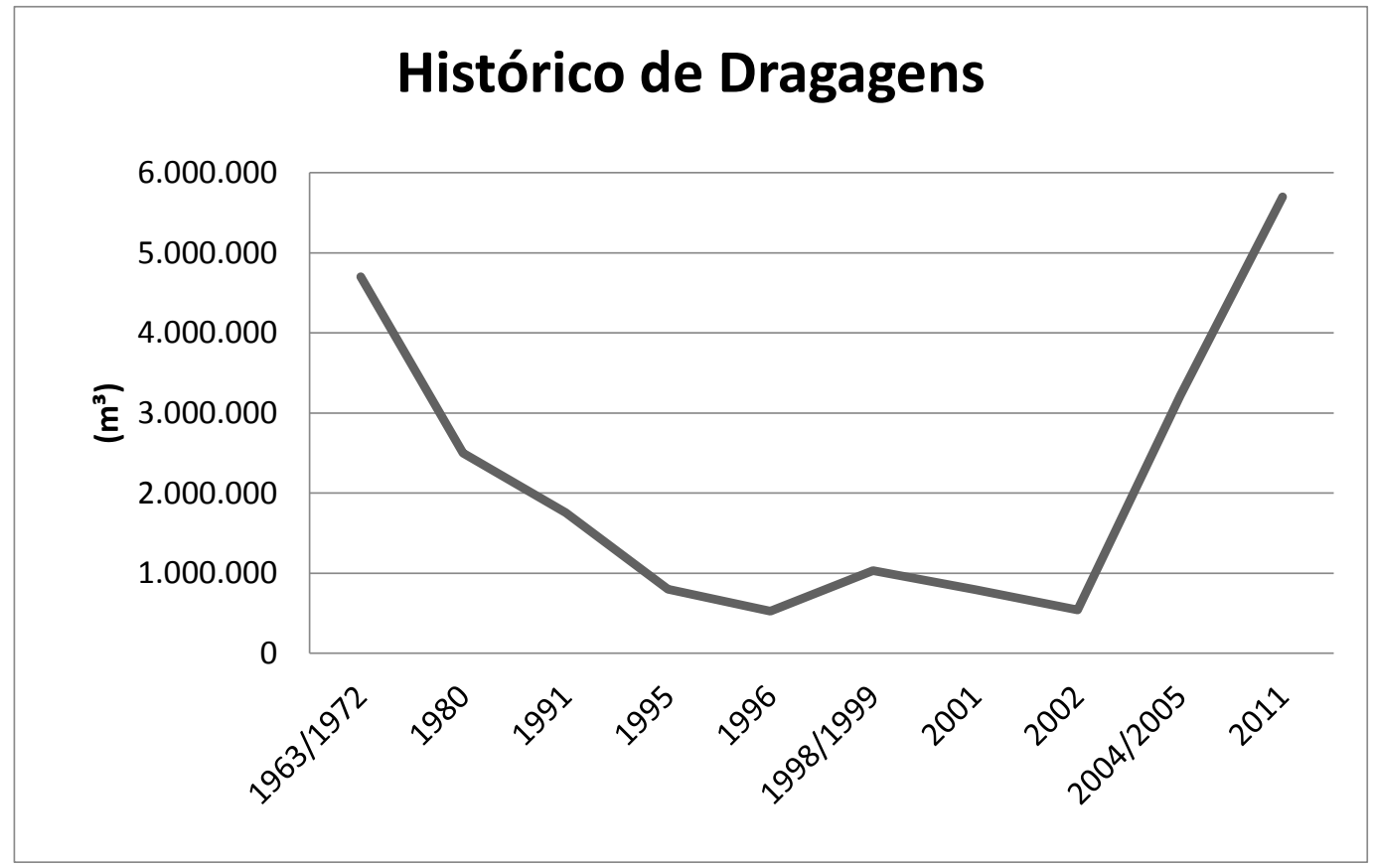

Figura 7 - Histórico de mais de quarenta anos de dragagens no Porto do Mucuripe. Fonte: CDC; Belmino (2015).

A figura 7 demonstra a grande quantidade de dragagens realizadas na bacia de evolução do Porto do Mucuripe entre 1963 e 2011. Em áreas portuárias a taxa de sedimentação tende a ser elevada, onde no Porto de Wellington na Nova Zelândia, a taxa de sedimentação anual é entre 3 a 5 mm (Goff et al., 1998).

Padrões Morfológicos associados ao Setor 2

É importante salientar, a considerável presença de substrato rochoso, no setor oeste da área estudada (Figura 8). Destacam-se como fundo rochoso o Recife do Meireles (defronte ao Meireles), Recife Grande (defronte ao quebra-mar Hawkshaw), Recife da Velha (ao norte do Recife Grande) e a Pedra do Justin (defronte a ponte dos Ingleses)

Conforme Ximenes Neto (2015) este setor além de apresentar a presença de blocos e 
complexos rochosos possui grande presença de micro e macro feições arenosas do tipo sand ripples e dunas subaquosas.

O emissário de Fortaleza ocorre defronte à Praia da Leste e apresenta cerca de 3.000 metros de comprimento. Logo após a oeste desta estrutura é localizado uma área de descarte dos sedimentos dragados do substrato adjacente ao porto. A principal macrofeição identificada e que apresentou morfodinâmica variável a partir da instalação do molhe do Titã e espigão do Titanzinho foi um banco alinhado a NW do porto. Como retrata Petcon (2002) e Oliveira (2013), este banco orientado a noroeste da ponta do Mucuripe existia antes do porto, pois com o volume sedimentar transportado pela deriva longitudinal costeira seria improvável formar uma feição desta dimensão.

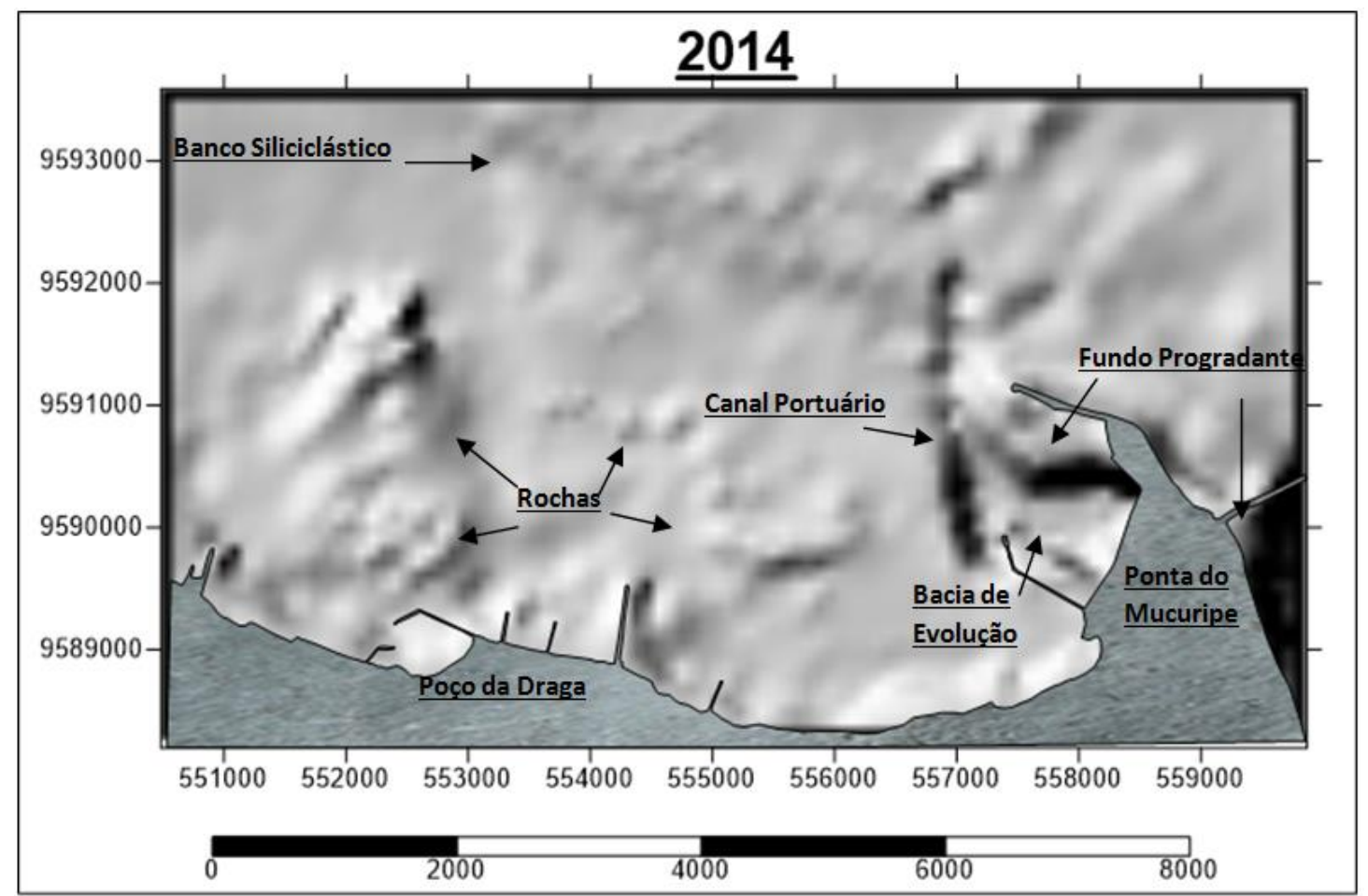

Figura 8 - Padrões Morfológicos do litoral norte de Fortaleza. Destacam-se os complexos rochosos entre a enseada do Mucuripe e o Emissário.

Oliveira (2013) calculou a taxa de assoreamento do banco (a partir de dados de maré, onda e vento) em três possibilidades: sem molhes, só com o titã e com as duas estruturas (Titã e Titanzinho). Com isto, foi verificado que o molhe do porto foi responsável pelo crescimento do assoreamento do banco, devido à reorientação hidrodinâmica. É importante salientar que o Titanzinho reteve uma considerável quantidade de sedimentos, porém não impediu que parte dos sedimentos fosse depositada no banco, na bacia portuária e a jusante (Morais, 1972; Oliveira, 2013). Verifica-se que as ondas são o principal agente hidrodinâmico modificador do banco e o aumento da ocorrência de ondas sea vindas de leste favorece uma maior sedimentação no banco (Oliveira, 2013).

Sendo assim, observou-se que o banco siliciclástico alinhado pelo promontório do
Mucuripe existia antes da instalação do porto. A gênese para esta feição geomorfológica está associada às características fisiográficas, sedimentares e hidrodinâmicas (local e eustatismo). Acredita-se que este banco seja produto da associação entre a morfodinâmica costeira do entorno do promontório do Mucuripe e a subida do nível relativo do mar do Holoceno (transgressão Flandriana). Nas proximidades de promontórios existe a formação de feições arenosas do tipo banco devido à relação mudanças fisiográficas e hidrodinâmica (Dyer \& Huntley, 1999; Berthot \& Pattiaratchi, 2006; Bastos et al., 2003 e Neill \& Scourse, 2009).

Acredita-se que assim como no Golfo de Cadiz na Espanha (Castro et al., 2017), a subida do nível do mar e a paleofisiografia associada a promontório e alinhamentos rochosos favoreceram a formação deste banco. 
Assumindo a curva holocênica de Bezerra et al., (2003) para a costa do Rio Grande do Norte, evidencia-se que a 5.000 anos A.P o nível do mar se elevou 3-4 metros acima da cota atual. Desta forma, ainda na fase de subida quando o nível do mar estava nos entornos da isóbata de 10 metros atual, aponta-se que o promontório do Mucuripe e os alinhamentos rochosos (Justin e Velha) apresentavam um importante papel de bypass hidrodinâmico e aerodinâmico. Favorecendo assim o desenvolvimento de bancos submersos e até barreiras costeiras (ilhas e spits) no setor a sotamar da ponta. Isto possivelmente foi intensificado pelo fato do promontório nitidamente dividir dois setores de antigas linhas de costa: NNW-SSE e NW-SE.

Assumindo que esta mudança fisiográfica associada à elevada disponibilidade de sedimentos transportados pela deriva, assim como aponta atualmente Maia (1998) de
$860.000 \mathrm{~m}^{3}$ /ano para o setor NNW-SSE (Praia do Futuro) favorecia o desenvolvimento de formas de fundo subaquosas (bancos) e emersas (barreiras costeiras).

Analisando a variabilidade espaço-temporal da isóbata de 10 metros na região do banco foi verificado sua elevada morfodinâmica. Analisou-se o período de 1969-2014 devido à carta náutica de 1945/1952 apresentar poucos pontos batimétricos na região do banco e a de 1959 ser muito similar a de 1969 . No primeiro intervalo de tempo analisado - 1969 a 1987 foi verificado um grande crescimento do banco a NW e de largura entre 1969-1979, destaca-se que o Titã foi prolongado para 1.900 metros e que em 1974 o espigão do Titanzinho foi prolongado de 550 metros para 990 metros. Entre 1979-1987 o banco se estreita e se desmembra em alguns pontos, principalmente próximo do Titã (Figura 9).

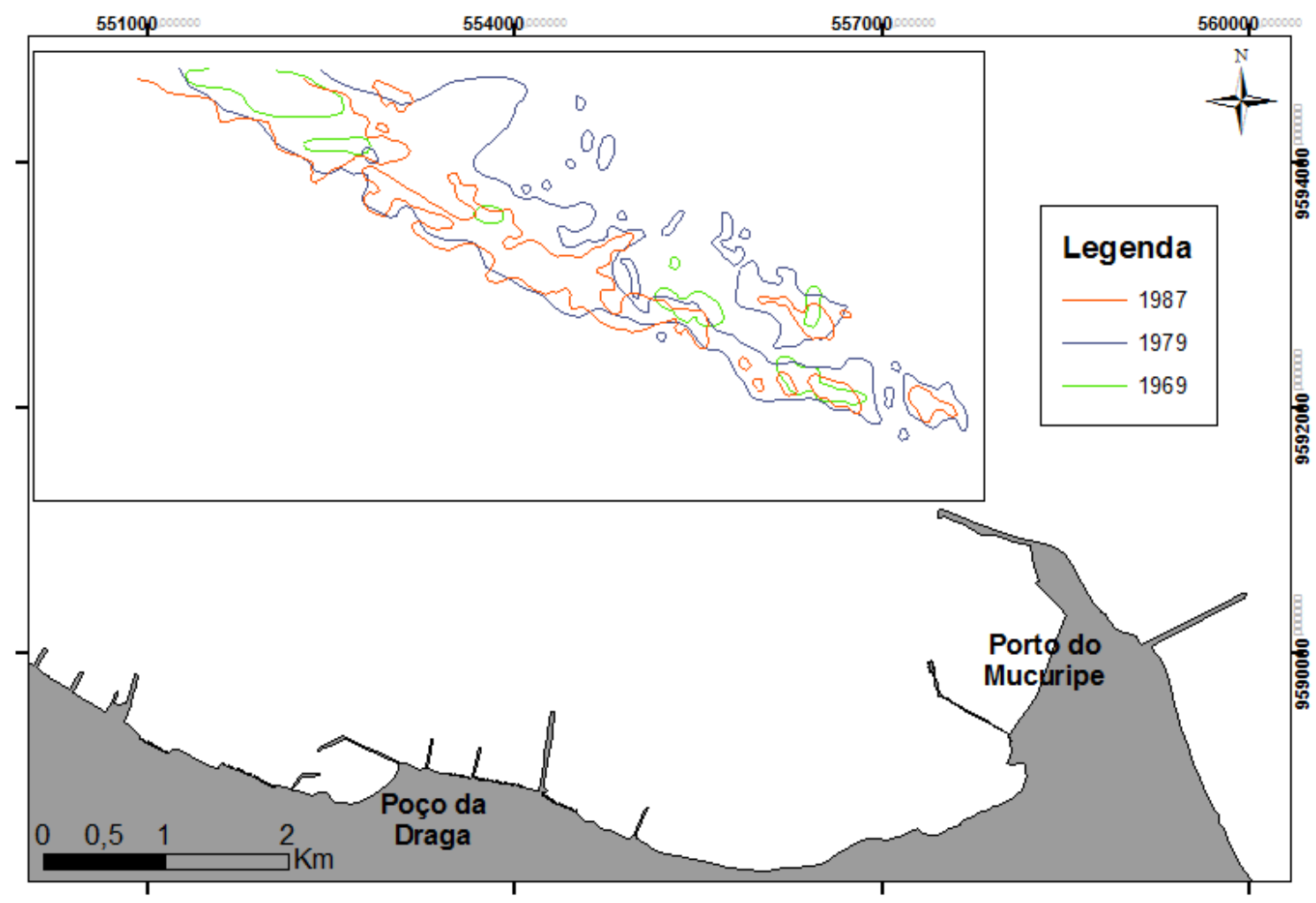

Figura 9 - Morfodinâmica da isóbata de 10 metros associada ao banco de Fortaleza entre 1969-1987.

No segundo intervalo de tempo analisado 1999-2014 não houve atualizações de informações batimétricas para os setores terminais do banco, sendo atualizada apenas nas proximidades do porto (Figura 10). Em relação ao último padrão (1987), em 1999 houve um novo crescimento lateral do banco, progradação esta que foi até 2010.

Porém em 2014 verificou-se uma nova readaptação da isóbata de $10 \mathrm{~m}$, com o estreitamento e desmembramento do banco. Destaca-se que neste período novas etapas de dragagem ocorreram e que o prolongamento do canal de acesso destruiu o início do banco (norte da ponta do Titã).

Destaca-se que esta mutabilidade da isóbata de 10 metros no banco ocorreu na tentativa da readaptação motivada por intervenções na 
região intertidal e antepraia, onde os processos hidrodinâmicos também se readaptam a estas intervenções. Desta forma, qualquer alteração nos padrões ondulatórios e das correntes paralelas à costa (deriva litorânea) influencia no padrão morfológico da feição.

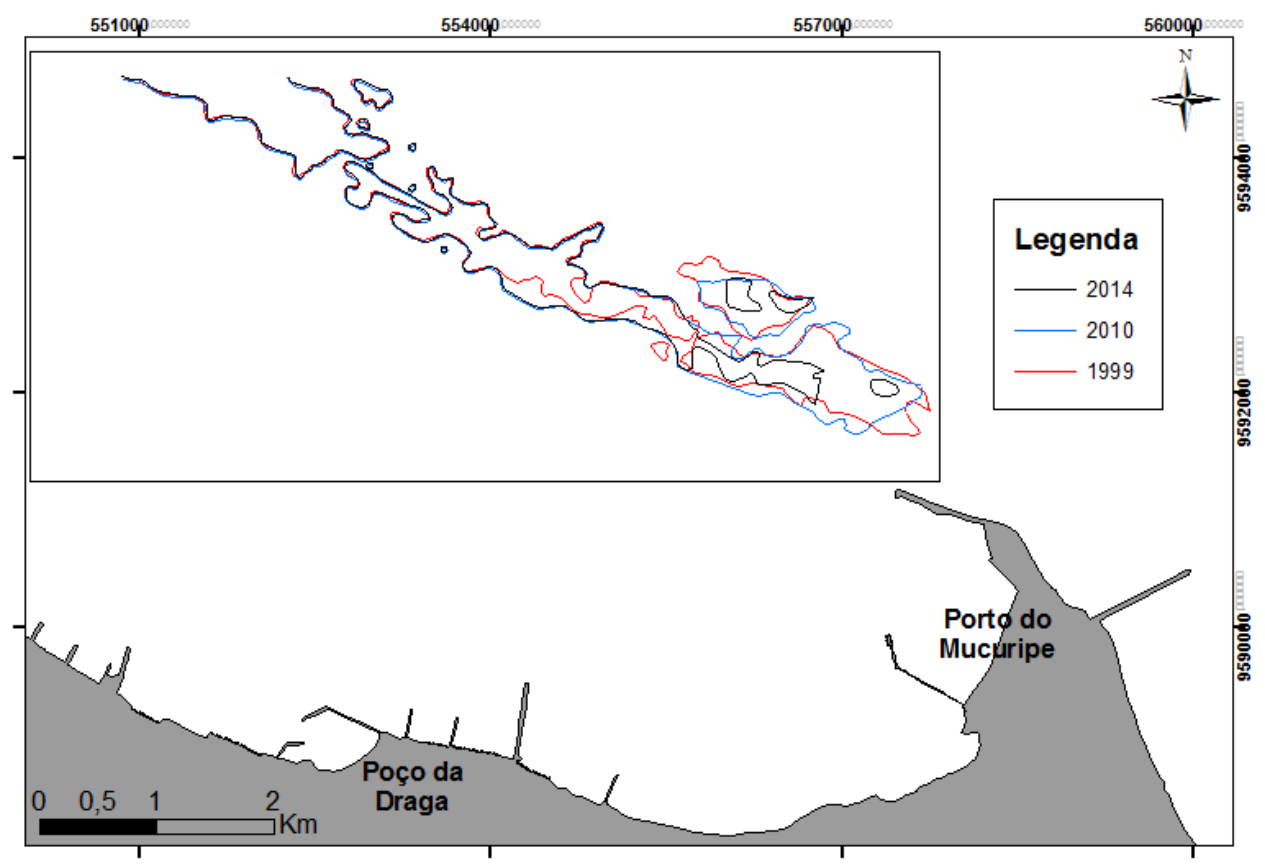

Figura 10 - Morfodinâmica da isóbata de 10 metros associada ao banco de Fortaleza entre 1999-2014.

Sendo assim, os principais fatores que interferiram na morfodinâmica do banco é a relação entre $o$ agente hidrodinâmico (direção, intensidade) e os sedimentos (granulometria, aporte sedimentar). Após a última grande intervenção na costa (prolongamento do Titanzinho) o banco ainda se alterou, demonstrando que os processos atuam remodelando-o (talvez até de forma cíclica).

De acordo com Soares (2012) este banco apresenta predomínio de sedimentos grossos (58\%). Ximenes Neto et al. (2013) identificou duas respostas acústicas associadas ao banco (ecocaráter), sendo o eco sem refletores em subsuperfície e elevado coeficiente de reflexão associado aos sedimentos grossos. O outro eco apresentava um raso refletor em subsuperfície, possivelmente associado a sedimentos mais finos. Demonstrando assim, que esta grande feição apresenta uma grande variabilidade granulométrica. $\mathrm{O}$ banco siliciclástico se apresenta hoje com cerca de $2,050 \mathrm{Km}^{2}$ e nitidamente delimitado pela isóbata de 10 metros. Maia (1998) estimou um volume para esta macrofeição de $12.300 .000 \mathrm{~m}^{3}$.

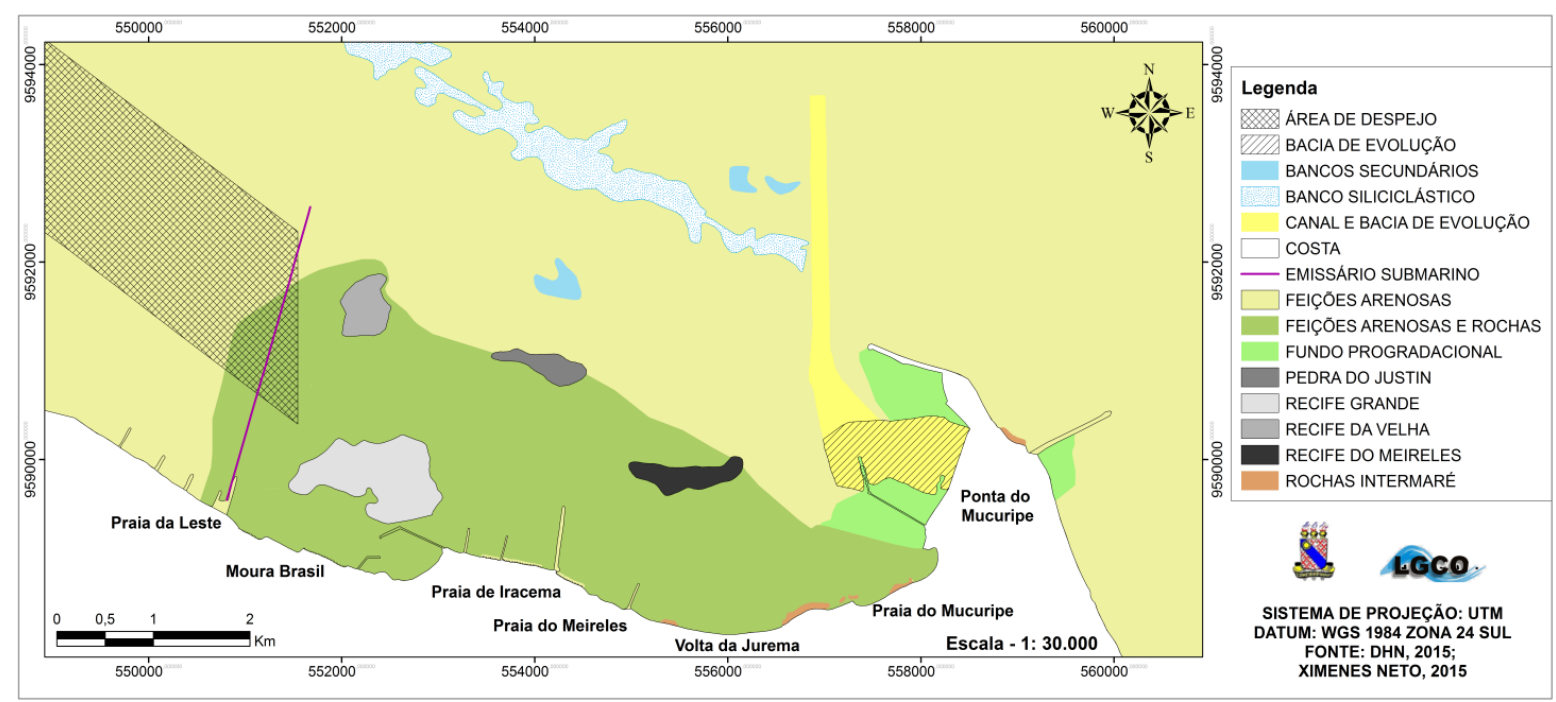

Figura 11 - Paisagem Submarina do Litoral Norte de Fortaleza. 


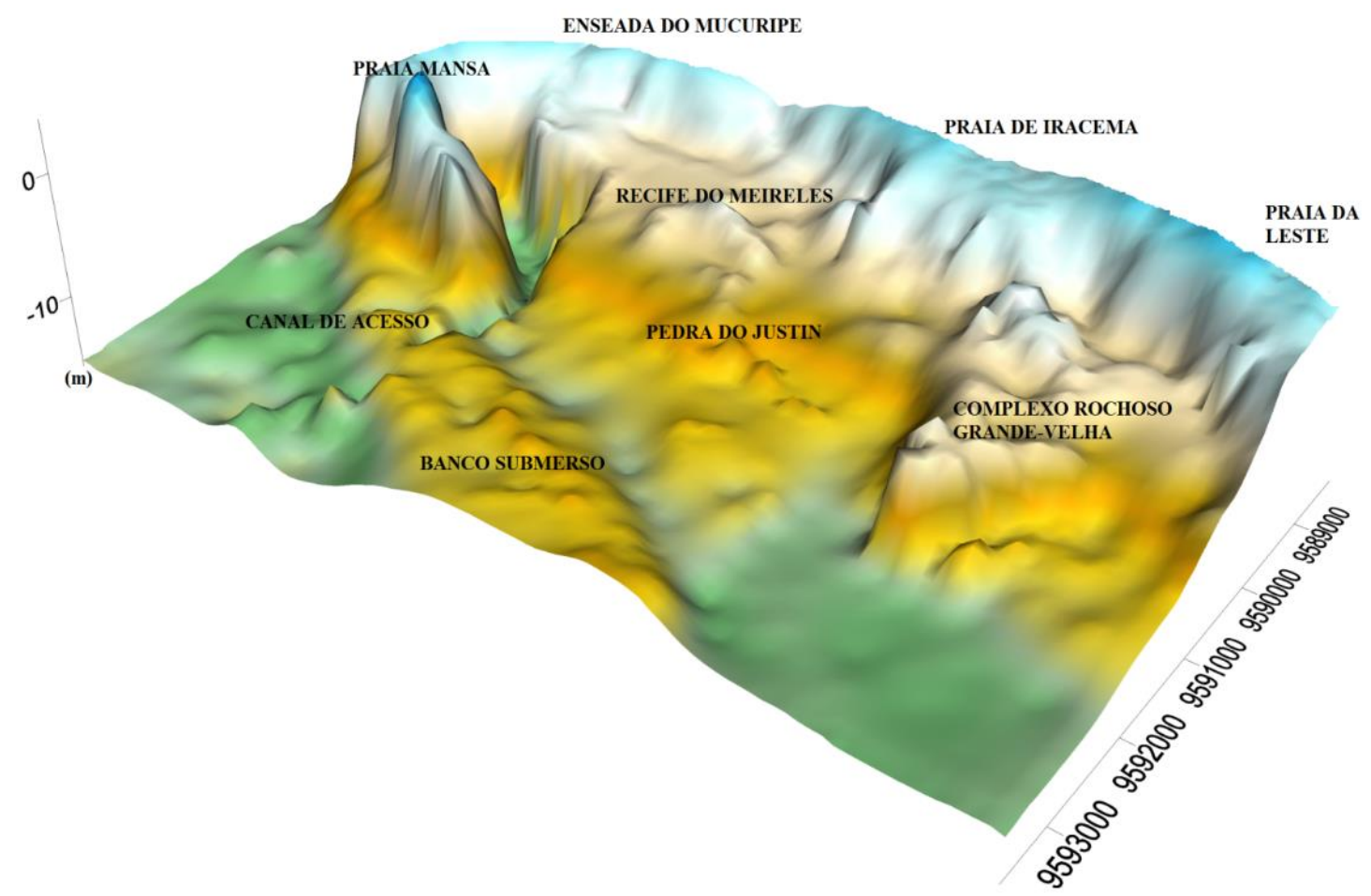

Figura 12 - Modelo Batimétrico tridimensional do litoral norte submarino de Fortaleza.
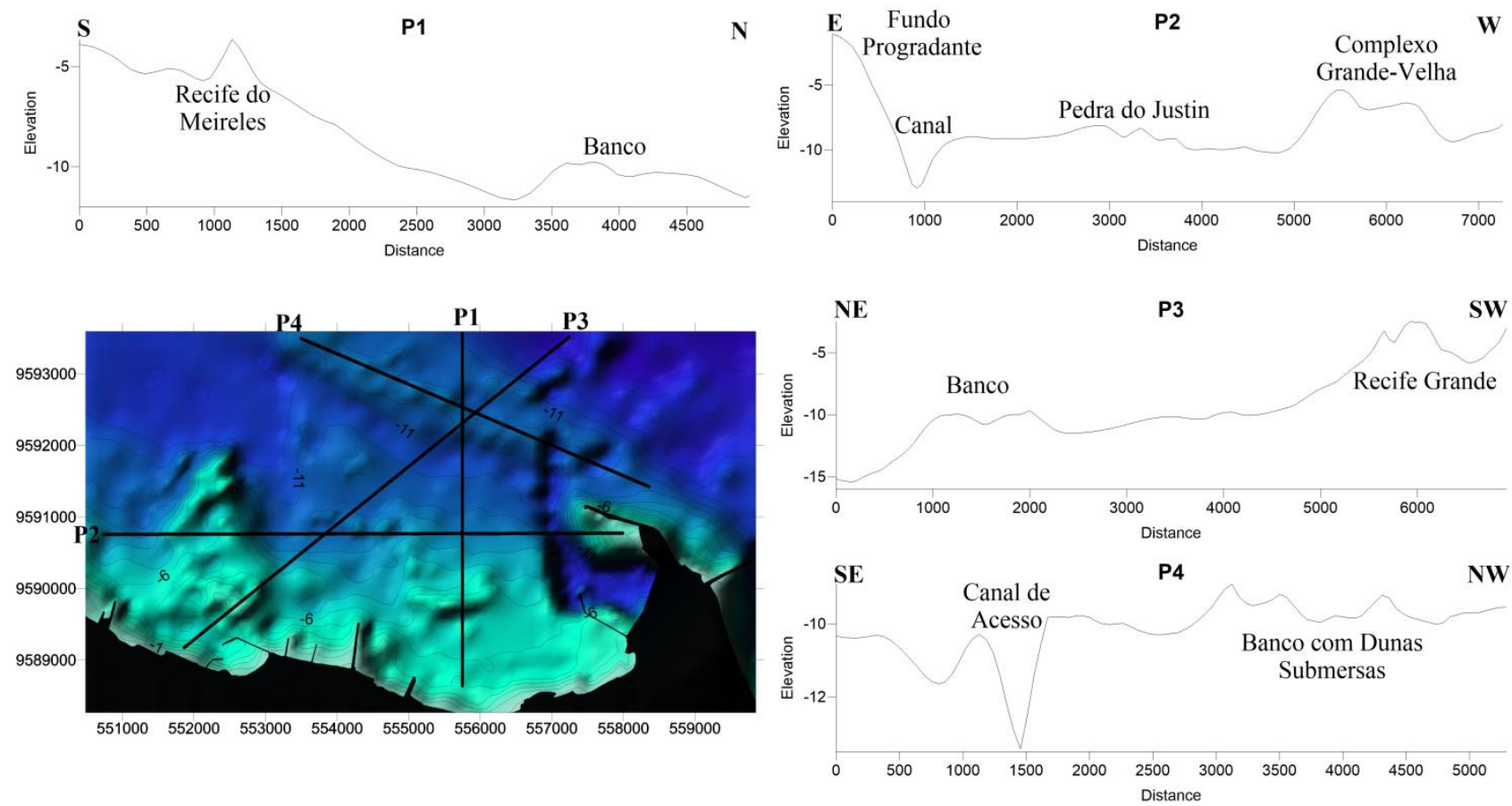

Figura 13 - Perfis batimétricos das principais feições que caracterizam a paisagem submersa do litoral norte de Fortaleza.

A figura 11 representa as feições que caracterizam a paisagem submarina do litoral norte de Fortaleza-CE. Destaca-se que no limite oeste da área estudada foi verificada uma área destinada ao descarte dos materiais dragados no Porto do Mucuripe. De acordo com Catunda (2013), o descarte de sedimentos nesta área se dispõe de maneira irregular, além de apresentar setores com elevadas concentrações de matéria orgânica.
Verifica-se na figura 12 que o Recife Grande e o Recife da Velha formam um complexo rochoso. A constituição litológica destes relevos positivos que ocorrem desde a enseada do Mucuripe até o emissário submarino pode estar associada ao Grupo Barreiras, devido aos afloramentos no estirâncio (Morais, 1967).

Analisando as figuras 11 a 14 se verifica que depois da influência antrópica na conformação 
morfológica do setor 1, aparece o importante papel fisiográfico desempenhado pelo embasamento rochoso, seja pelo promontório do Mucuripe ou todos os relevos submersos. A figura 14 demonstra o principal complexo rochoso do litoral submarino de Fortaleza (Grande-Velha).

Sendo que nos perfis perpendiculares, a feição apresentou heterogeneidades batimétricas, a principal seria um setor depressivo que separa os dois altos que formam os recifes Grande e da Velha. A diferença batimétrica
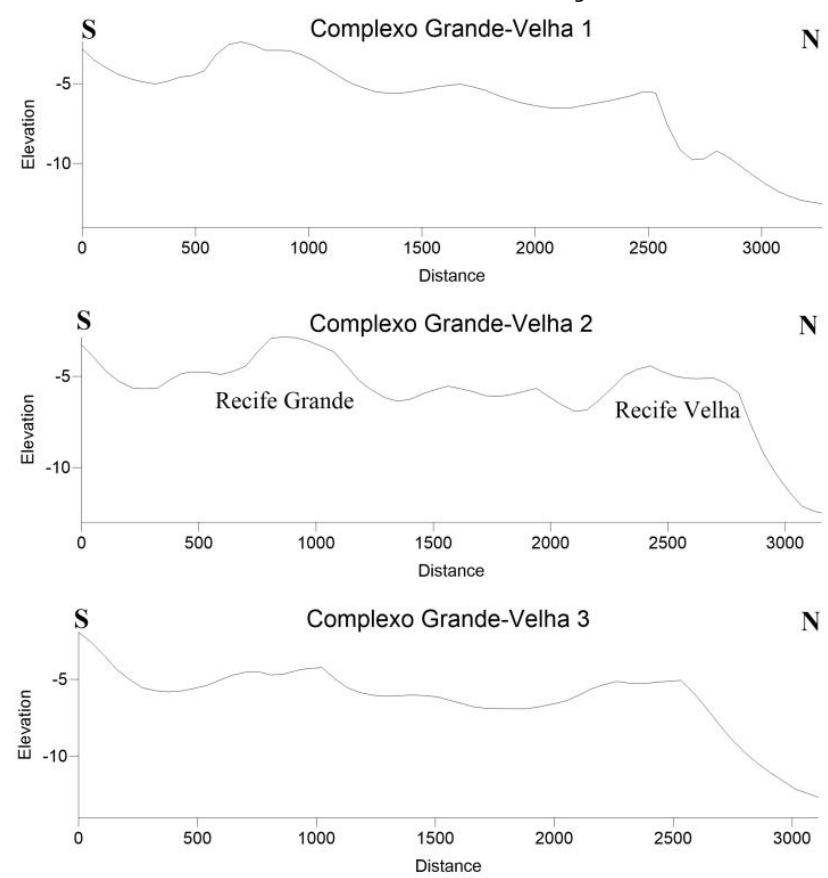

mais significativa entre o Complexo GrandeVelha e o piso marinho relativamente planar ocorre no limite norte, onde são verificadas diferenças batimétricas de 5-6 metros (declividade de 0,045). Nos perfis paralelos foram observados os nítidos altos batimétricos, com até 5-6 metros de altura.

Destaca-se que a maior declividade de relevo ocorre associada às margens do canal de acesso portuário, apresentando diferenças batimétricas de 13-14 metros e valores de até 0,08 de declividade (Figura 13).
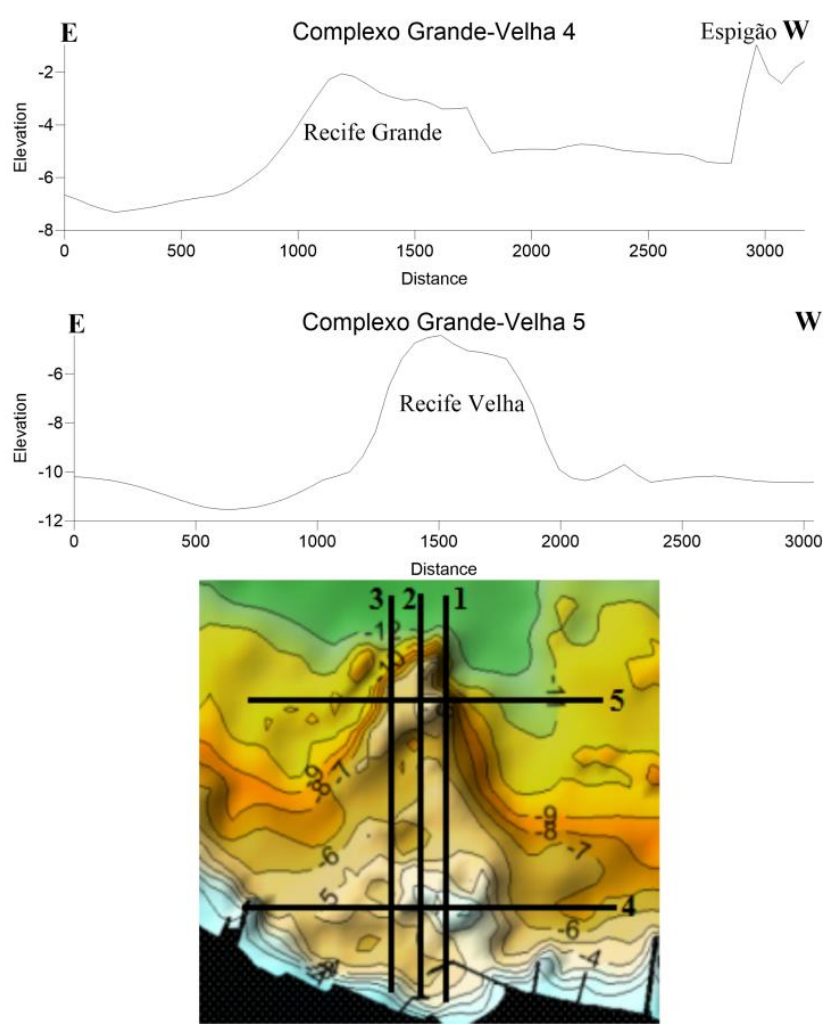

Figura 14 - Perfis paralelos e perpendiculares ao complexo rochoso Grande - Velha.

\section{CONCLUSÃO}

A paisagem submarina do litoral norte de Fortaleza apresentou grandes modificações morfológicas desde a década de 1940, principalmente no entorno do porto do Mucuripe. Vale ressaltar também que as principais estruturas responsáveis pelos processos erosivos e deposicionais na costa e na plataforma interna foram às obras rígidas de proteção e operação portuária - molhe do Titã, espigão do Titanzinho, Píer petroleiro e o Cais comercial.
As principais formas que apresentaram o fator antrópico como principal agente formador foram: a bacia de evolução, o canal de acesso, a Praia Mansa e o barlamar do Titanzinho (tanto na costa como no setor submarino).

O banco a NW do Titã apresenta o agente antrópico com importância na sua morfodinâmica, porém a sua gênese paleogeográfica está associada a fatores físiconaturais durante $o$ fim da transgressão Holocênica.

\section{AGRADECIMENTOS}

Ao CNPq e ao Projeto "Potencialidades e Manejo Ambiental na Exploração de Granulados da Plataforma Continental do Estado do Ceará" pelo auxílio financeiro e suporte técnico. 


\section{REFERÊNCIAS}

ALLEN, J.R.L. Sedimentary structures their character and physical basis I e II. Development in Sedimentology. Elsevier, 1982.

ASHLEY, G. Classification of large-scale subaqueous bedforms: a new look at an old problem. Journal of Sedimentary Petrology, v. 60, p. 160-172, 1990.

BASTOS, A; COLLINS, M; KENYON, N. Water and sediment movement around a coastal headland: Portland Bill, southern UK. Ocean Dynamics, v. 53, p. 309-321, 2003.

BELMINO, I.K.C. Comportamento geoquímico do mercúrio em áreas portuárias: estudo de caso do porto do Mucuripe, Fortaleza-Ceará. Fortaleza, 2015. Monografia de Graduação em Ciências Ambientais - Instituto de Ciências do Mar.

BERTHOT, A. \& PATTIARATCHI, C. Mechanisms for the formation of headland-associated linear sandbanks. Continental Shelf Research, v. 26, p. 987-1004, 2006.

BOGGS JR, S. Principles of Sedimentology and Stratigraphy. 4th ed. University of Oregon, 2006.

BEZERRA, F.H.R; BARRETO, A.M.F; SUGUIO, K. Holocene sea-level history on the Rio Grande do Norte State coast, Brazil. Marine Geology, v. 196, p. 73-89, 2003.

CATUNDA, B.N. Caracterização da área destinada ao descarte de sedimentos dragados no Porto de Fortaleza/CE: análise textural e morfológica. Fortaleza, 2013. Monografia de Graduação em Oceanografia - Instituto de Ciências do Mar.

CASTRO, S; LOBO, F.J; PUGA-BERNABÉU, A. Headland associated banner banks generated during the last deglaciation near the Strait of Gibraltar (Gulf of Cadiz, SW Spain). Marine Geology, v. 386, p. 56-75, 2017.

CDC - COMPANHIA DOCAS DO CEARÁ. Projeto da $\mathbf{2}^{\mathbf{a}}$ etapa da dragagem de aprofundamento do porto de Fortaleza. $2010-$ CDC.

DYER, K.R. \& HUNTLEY, D.A. The origin, classification and modelling of sand banks and ridges. Continental Shelf Research, v. 19, p. 1285-1330, 1999.

GOFF, J.R; WHITEHEAD, N.E; DITCHBURN, R.G. ${ }^{210} \mathrm{~Pb}$ chronology from Wellington Harbour, New Zealand. New Zealand Journal of Marine and Freshwater Research, v. 32, n. 2, p. 181-186, 1998.

HEEZEN, B.C., THARP, M; EWING, M. 1959. The floors of the oceans; I, The North Atlantic: Geological Society of America Special Paper 30, v. 65, 122p.

MAIA, L.P. Procesos y balance sedimentário a ló largo de Fortaleza (NE-Brasil): implicaciones para uma gestión adecuada de La zona litoral. 1998. 281p. Tese (Doutorado em ciências Del mar) - Facultat de Geologia, Universitat de Barcelona, Barcelona, 1998.

MORAIS, J.O. 1981. Evolução sedimentológica da Enseada do Mucuripe. Arquivo de Ciências do Mar, v. 21, p. 19-46.

MORAIS, J.O. Processo de assoreamento do Porto de Mucuripe. Arquivo Ciências do Mar 12, p. 139-149, 1972.

MORAIS, J.O. 1969. Contribuição ao Estudo de "BeachRocks" do Nordeste do Brasil. Trab. Oceanog. Universidade Federal de Pernambuco, 1967-1969. Recife 9-11, 79-94.
NEILL, S.P. \& SCOURSE, J.D. The formation of headland/island sandbanks. Continental Shelf Research, v. 29, p. 2167-2177, 2009.

OLIVEIRA, R.B.P.L. Evolução Batimétrica do Banco Arenoso ao Largo do Porto de Mucuripe (Fortaleza - CE). Rio de Janeiro, 2013. Dissertação de Mestrado, COPPE.

PAULA, DP. Análise dos riscos de erosão costeira no litoral de Fortaleza em função da vulnerabilidade aos processos geogênicos e antropogênicos. Portugal, 2012. Tese (Doutorado) em Ciências do Mar, Algarve.

PETCON - Planejamento, engenharia, transporte e consultoria. Estudo objetivando definir as causas do assoreamento do Porto de Fortaleza. Companhia Docas do Ceará, FortalezaCE, p. 101, 2000.

PITOMBEIRA, E.S. Deformação das ondas por difração no molhe do Porto do Mucuripe (Fortaleza - Ceará - Brazil). Fortaleza, 1976. Laboratório de Ciências do Mar.Universidade Federal do Ceará.

SOARES, R.C. Evolução e Caracterização do Banco Sedimentar de Fortaleza, Ceará, Brasil. Fortaleza, 2012. 116p. Dissertação de Mestrado. Universidade Estadual do Ceará-UECE

VALENTINI, E.M.S. Avaliação de processos litorâneos e consequências para o gerenciamento costeiro no ceará. Rio de Janeiro. 1994. Tese (Doutorado) - Curso de Ciências em Engenharia Oceânica, Universidade Federal do Rio de Janeiro.

VALENTINI, E. \& ROSMAN, P.C.C. Erosão Costeira em Fortaleza. Revista Brasileira de Engenharia, v. 10, p. 12, 1992.

XIMENES NETO, A.R. Evolução da paisagem submarina do litoral norte de Fortaleza - CE. Monografia de Graduação em Geografia - UECE, 2015.

XIMENES NETO, A.R. \& MORAIS, J.O. Evolução geomorfológica da área submersa adjacente a ponta do Mucuripe - Fortaleza. In: SEMANA UNIVERSITÁRIA DA UECE, XX, 2015, Fortaleza. Anais... Fortaleza: Semana Universitária da UECE, 2015.

XIMENES NETO, A.R.; PAULA, L.F.S; MORAIS, J.O. Utilização da Perfilagem Sísmica de Subsuperfície para Análise do Banco Sedimentar de Fortaleza. In: SEMANA UNIVERSITÁRIA DA UECE, XVIII, 2013, Fortaleza. Anais... Fortaleza: Semana Universitária da UECE, 2013.

XIMENES NETO, A.R.; MORAIS, J.O; PINHEIRO, L.S. Distribuição das formas de fundo e padrões sedimentares no porto do Mucuripe, Fortaleza-Ceará. Revista Brasileira de Geomorfologia (Online), São Paulo, v.19, n. 2, p.321-339, 2018. 